\title{
STUDY OF AIRCRAFT WING FLAP HYDRAULIC SYSTEM DYNAMICS UNDER DAMAGES DUE TO OPERATING AN AIRCRAFT
}

\section{BADANIA DYNAMIKI UKLADU HYDRAULICZNEGO KLAP SKRZYDLA SAMOLOTU Z UWZGLECDNIENIEM USZKODZEŃ EKSPLOATACYJNYCH}

\author{
Józef Błachnio ${ }^{1}$ Andrzej Gronczewski \\ (1) Air Force Institute of Technology \\ Instytut Techniczny Wojsk Lotniczych \\ 01-494 Warszawa ul. Księcia Bolesława 6 \\ (2) Wrocław University of Technology \\ 50-370 Wroclaw ul. Wybrzeze Wyspienskiego 27 \\ e-mail: (1) jozef.blachnio@itwl.pl (2) andrzej.gronczewski@pwr.wroc.pl
}

\begin{abstract}
The paper indicates the main reasons for faulty operation of aeroplane wing flap hydraulic systems. A mathematical model of the wing flap dynamics has been presented, allowing an analysis of a simulation study taking into account damages due to usual wear and tear during operating of a plane.
\end{abstract}

Keywords: aircraft, wing flaps, hydraulic system, model of dynamics, simulation.

Streszczenie. W artykule zasygnalizowano główne przyczyny nieprawidłowej pracy układu hydraulicznego klap skrzydła samolotu. Przedstawiono opracowany model matematyczny dynamiki układu klap skrzydła, umożliwiający badania symulacyjne $\mathrm{z}$ uwzględnieniem uszkodzeń eksploatacyjnych. Główny nacisk położono na analizę wyników badań symulacyjnych dynamiki układu hydraulicznego.

Słowa kluczowe: samolot, klapy skrzydła, układ hydrauliczny, model dynamiki 


\section{STUDY OF AIRCRAFT WING FLAP HYDRAULIC SYSTEM DYNAMICS UNDER DAMAGES DUE TO OPERATING AN AIRCRAFT}

\section{Introduction}

The group of accidents occurring due to technical reasons includes events which resulted directly from faulty operation of hydraulically powered/operated wing mechanisms. Operational experience allowed to distinguish reasons for a faulty operation of a hydraulic system operating mechanical wing elements. Statistical data $[2,4,8,11]$ show that $15 \%$ of all damages to aircrafts are damages to hydraulic systems. Damages occurred mostly of component hydraulic system, to pumping systems of installations, however, a substantial number of damages to hydraulic systems are damages to hydraulic systems controlling and operating wing elements (Fig.1).

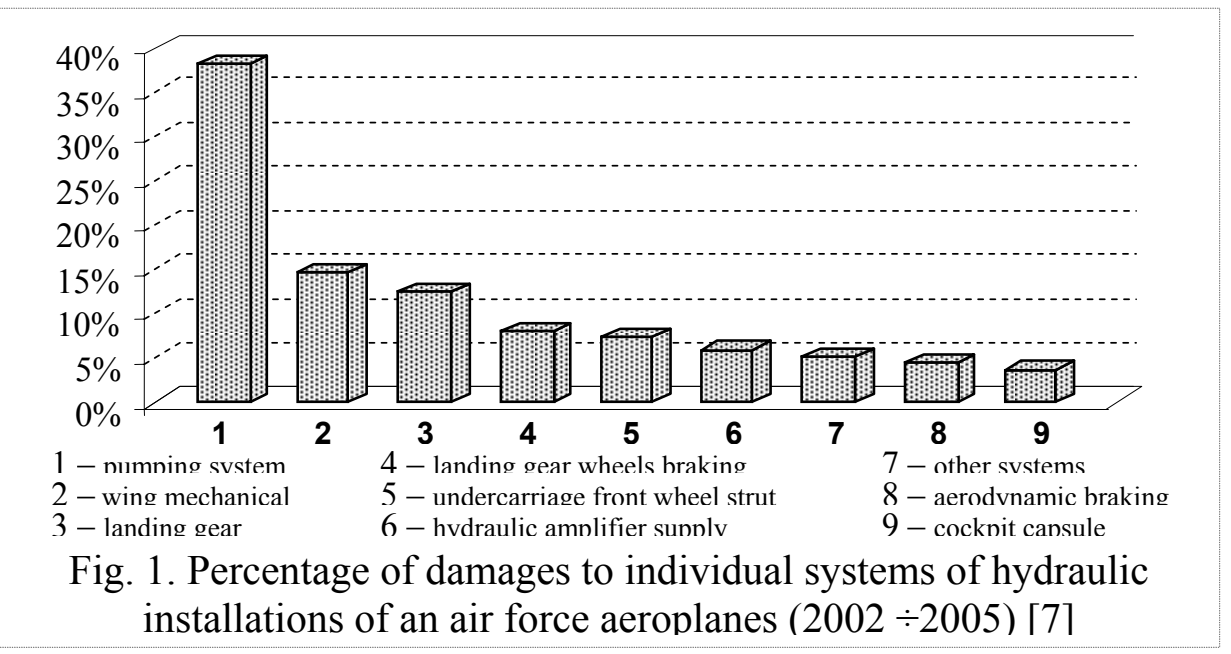

Studies and operational/flight experience show that a faulty operation of wing mechanical systems can result from: $[5,7,11]$ :

$>$ a damage to the kinematical system and to mounting points of wing element operating parts;

improper operation of the hydraulic system. 
Improper operation of the hydraulic system operating wing elements may be mainly caused by:

$>$ leakages to the outside (leaking hydraulic power lines);

internal leakages (leaking executive elements).

\section{Mathematical model of a wing flaps hydraulic system}

For a model of the wing flaps hydraulic system assumptions as follows have been made:

$>$ only one kind of flow is assumed;

$>$ cavitation does not occur;

$>$ the elasticity of hydraulic line walls is neglected;

$>$ the flow through slots is a laminar one and proportional to pressure;

$>$ medium physical properties do not change;

$>$ the only throttling effect occurs at the distribution valve;

$>$ pump pulsations during transient states are neglected;

$>$ zero overlap distribution valves were used.

With all these assumptions a simplified system scheme and denotations as presented in Fig. 2.1 were adopted.

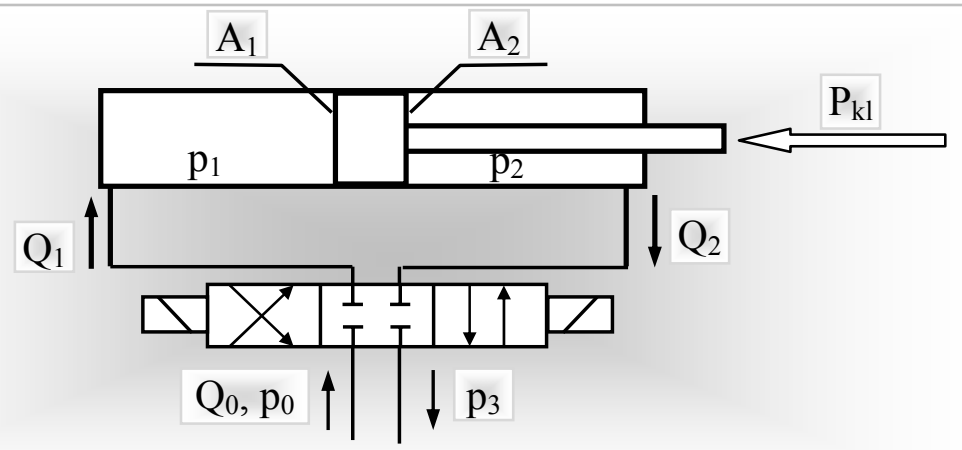

Fig. 2. Wing flaps hydraulic system operating scheme

The adopted mathematical model is based on a balance of working fluid flow rates and an actuator circuit motion equations. The flow rates balance:

$Q_{1}=Q_{P}+Q_{H 1}+Q_{S I}+Q_{V}$

$\boldsymbol{Q}_{2}=\boldsymbol{Q}_{H_{2}}+\boldsymbol{Q}_{S 2}+\boldsymbol{Q}_{V}$ 
The actuator circuit motion balance:

$m \frac{d^{2} y}{d t^{2}}+B \frac{d y}{d t}+P_{S}=A_{1} p_{1}-A_{2} p_{2}$

After introduction of dependences for individual working medium flow rates into the flow rates balance, the system transmittance will definitely take the following form:

$$
\begin{aligned}
& G(s)=\frac{Y(s)}{X(s)}=\frac{K}{T_{2} s^{2}+T_{1} s+1} \\
& K=\frac{\alpha \pi^{2} b \sqrt{p_{0}}\left(2 D^{2}-d^{2}\right)}{16 K_{V} N_{K L}} \quad T_{1}=\frac{m}{N_{K L}} T_{2}=\frac{B}{N_{K L}}+\frac{A^{2}}{2 K_{V} N_{K L}}\left(2-\frac{d^{2}}{D^{2}}\right)
\end{aligned}
$$

Where: $B$ - coefficient of viscotic friction; $b$ - distribution valve spool diameter; $D, d$-actuator piston diameter; $K_{V}$-volumetric loss factor; $m$ mass of the driven system; $N_{K L}$ - flap load coefficient; $p_{0}-$ working pressure; $\alpha$-flow factor; $\lambda$-flow rate distribution coefficient.

The values of the system transmittance factors $K, T_{1}, T_{2}$ are functions of system real parameters. Due to this the formulated mathematical model is to some extent universal as with it one can carry out simulation studies of hydraulic systems for wing flaps of various aeroplanes.

\section{Simulation study of the wing flap dynamics}

\subsection{Methods of simulation studies}

Studies were conducted to the following procedure:

$>$ Hydraulic system data were entered into the Matlab-Simulink programme;

Actuator rod travel values and the difference in actuator rod travels was computed;

$$
\Delta y(t)=y_{0}(t)-y_{Z}(t)
$$


The difference between aerodynamic forces acting on wing flaps was calculated:

$\Delta \boldsymbol{P}_{k l}(t)=\boldsymbol{P}_{k l 0}(t)-\boldsymbol{P}_{k l Z}(t)$

\subsection{System simulation study taking into account internal leaks inside an actuator}

Increased internal leakages in the actuator resulting from un-tightness at a piston can be due the following: ageing of sealing materials; contamination of the working fluid; working fluid parameters inconsistent with the system technical conditions, faults of manufacturing technology (e.g. increased roughness of the actuator internal surface). Internal leakages cause the volumetric flow in an actuator to diminish by a value given by the following formula:

$Q_{V}=K_{V}\left(p_{1}-p_{2}\right)$

The growth of the internal leakage is expressed as a percentage increment of the volumetric loss factor $\mathrm{K}_{\mathrm{v}}$ :

$\Delta K_{V}=\left(\frac{K_{V Z}}{K_{V 0}}-1\right) \cdot 100 \%$

The asymmetry of the deflection of wings is the reason for the difference of dynamic forces on them (Fig. 3, 4).

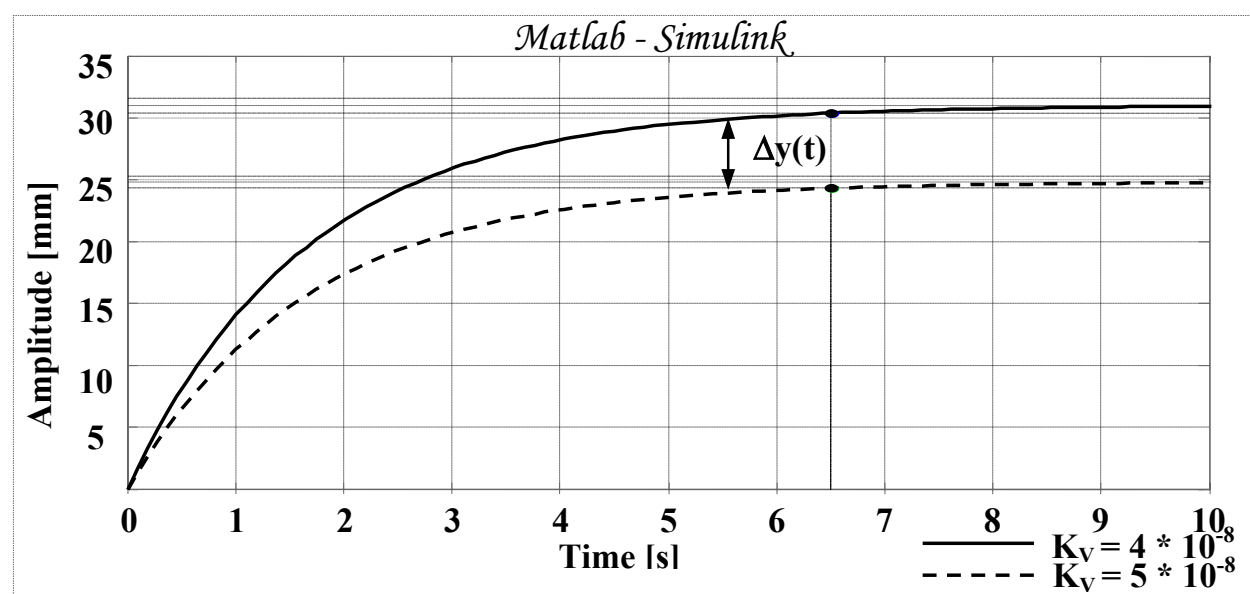

Fig. 3. System dynamics at growing internal leakages 


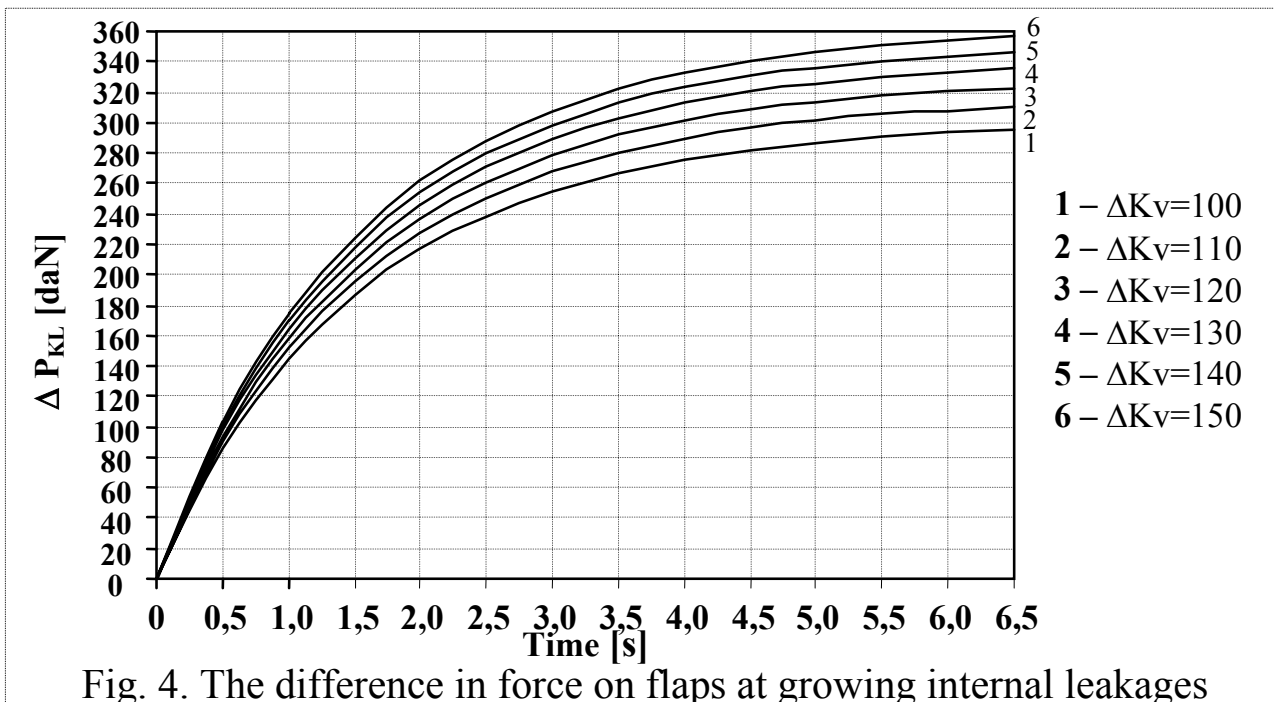

\subsection{Simulation study of a system taking in to account internal leakages}

One possible reason for system faulty operation can be its fluid leaking to the outside.

The main reasons of the hydraulic system leaking can be:

$>$ fatigue cracking of hydraulic lines;

$>$ leaking joints of lines;

$>$ faulty manufacturing of conduits;

$>$ mechanical damage to conduits;

$>$ other.

The study of the flap system dynamics was conducted at the following conditions/ assumptions:

$>$ working fluid leaking from an actuator pressure supply line;

$>$ un-tightness in one of the supply lines does not affect the operation of the second wing flap system;

$>$ the amount of leak during system operation is constant and expressed as a working pressure drop $\Delta \mathrm{p}$.

When a leakage to the outside as a result of un-tightness in the hydraulic system occurs it causes the wing flap actuator rods to travel asynchronously (Fig. 5). 


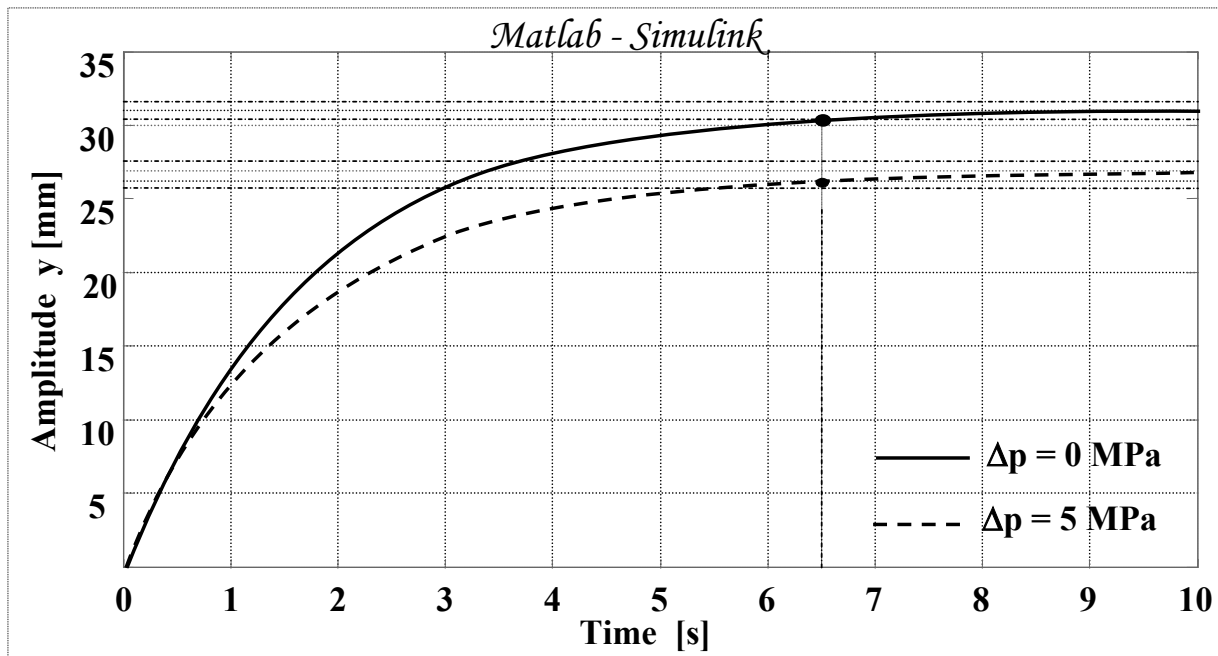

Fig. 5. System dynamics at external leakages

The asymmetry in the wing flap deflection causes a development a difference in the aerodynamic force on wings. (Fig.6).

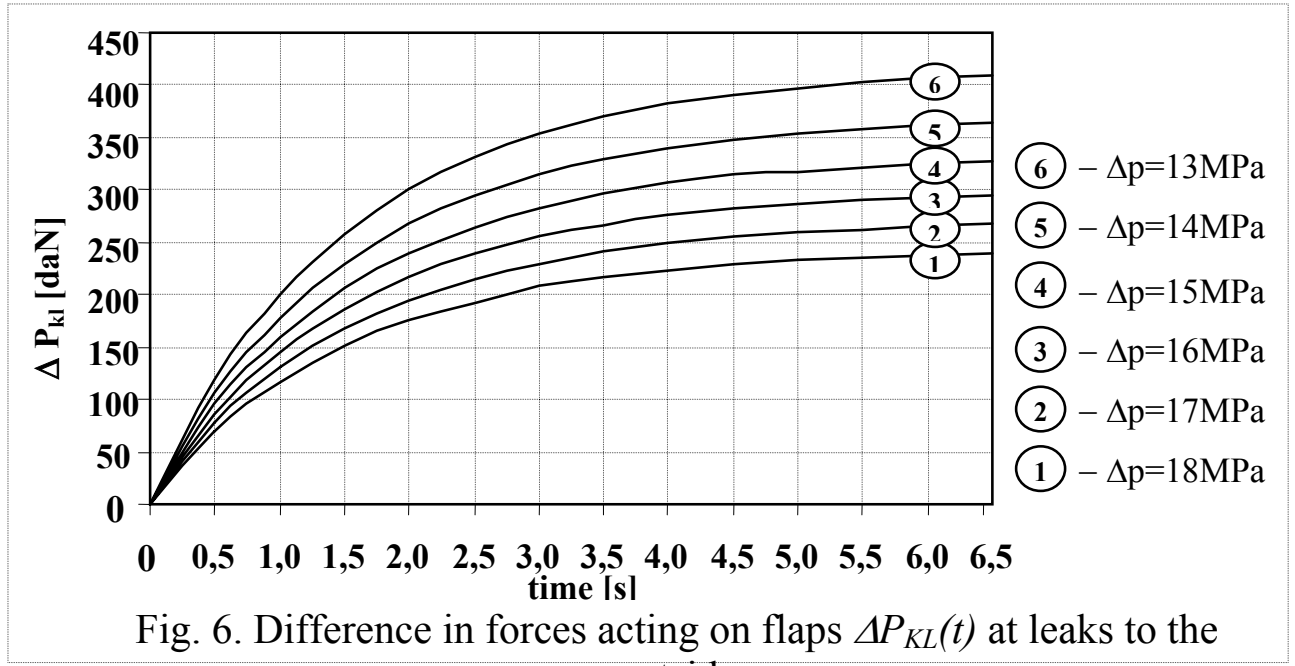

\section{Summary}

After the analysis of the design of a wing flap hydraulic system and basing on simulation study results and calculations for disturbances of different kinds one can draw the conclusions as follows: 
a) Disturbance: increased internal leakages in an actuator:

asymmetry of wing flap deflections over the entire working interval of a system;

$>$ the difference in flap deflection angle increases with the system operation time;

$>$ with increasing internal leakages the difference of the flap deflection angle increases;

$>$ should one of the flaps reach its maximum deflection angle both flaps will remain deflected asymmetrically at different angles;

$>$ the largest difference in flap deflections occurs during the first stage of system operation.

\section{b ) Disturbance: internal leakages:}

> flap deflection asymmetry over the entire operation time of a system;

$>$ the largest difference in flap deflections occur at the first stage of system operation;

should one of the flaps reach its maximum deflection angle both flaps will remain deflected at different angles;

with increasing internal leakages the difference of the flap deflection angle increases.

\section{Bibliography}

[1] Gronczewski A., Błachnio J.: Modelling of dynamic behaviour attributable to the two-output hydraulic system for driving mechanisms of aircraft wings. Research Works of Air Force Institute of Technology, No. 21, 2007.

[2] Gronczewski A.: Bezpieczeństwo lotu w ujęciu statystycznym. Journal of Transdiscyplinary System Science, Vol. 9, 2004.

[3] Gronczewski A.: Modelowanie układu hydraulicznego mechanizacji skrzydła samolotu z uwzględnieniem zaburzeń. Rozprawa doktorska. Instytut Techniczny Wojsk Lotniczych, Warszawa 2007 (not published).

[4] Klich E.: Służba Bezpieczeństwa w Wielkiej Brytanii. Przegląd Wojsk Lotniczych i Obrony Powietrznej No. 12/1998.

[5] Koggie Ju.K., Majskij R.A: Osnowy nadiożnosti awiacjonnoj tiechniki. Maszinostrojenije, Moscow, 1993. 
[6] Milkiewicz A. i inni: Podstawy organizacji i metodyki badania wypadków lotniczych w lotnictwie cywilnym RP. Główny Inspektorat Lotnictwa Cywilnego, Warszawa 2001.

[7] Opracowanie ITWL: Analiza niesprawności SP za lata $2003 \div 2005$. Instytut Techniczny Wojsk Lotniczych, Warszawa 2005.

[8] Statistical Summary of Commercial Jet Airplane Accidents Worldwide operations 1959 - 2002, Boeing 2002.

[9] Ułanowicz L., Zboiński M.: Ocena stanu technicznego lotniczych instalacji hydraulicznych w procesie ich eksploatacji. Problemy Badań i Eksploatacji Techniki Lotniczej, Nr. 5. Instytut Techniczny Wojsk Lotniczych, Warszawa 1987.

[10] Ułanowicz L.: Zarys oceny oczekiwanego czasu zdatności napędów hydraulicznych w eksploatacji Polska Akademia Nauk, Instytut Technologii Eksploatacji, Radom 2003.

[11] Zboiński M.: Zapobieganie stanom awaryjnym lotniczych układów hydraulicznych. Przegląd Wojsk Lotniczych i Obrony Powietrznej Nr. $7 / 1999$. 


\section{BADANIA DYNAMIKI UKLADU HYDRAULICZNEGO KLAP SKRZYDLA SAMOLOTU Z UWZGLEDNIENIEM USZKODZEŃ EKSPLOATACYJNYCH}

\section{Wstęp}

W grupie wypadków lotniczych z przyczyn technicznych, zawierają się zdarzenia, których bezpośrednią przyczyną było nieprawidłowe działanie układu hydraulicznego mechanizacji skrzydła. Z analizy dynamiki ruchu samolotu wynika, że w przypadku nieprawidłowej pracy układu hydraulicznego mechanizacji skrzydła, mogą wystapić zaburzenia równowagi jego ruchu.

Praktyka eksploatacyjna pozwala na wysublimowanie przyczyn niewłaściwej pracy układu hydraulicznego sterowania mechanizacją skrzydła. Wymagane jest jednak przeprowadzenie badań wpływu uszkodzeń na dynamikę układu sterowania mechanizacją skrzydła. $Z$ danych statystycznych $[2,4,8,11]$ wynika, iż wśród wszystkich uszkodzeń statków powietrznych (SP), około $15 \%$ stanowią uszkodzenia układów hydraulicznych.

Instalacje hydrauliczne współczesnych samolotów, składają się z wielu układów wykonawczych sterujących elementami i podzespołami statku powietrznego. Najwięcej uszkodzeń zaistniało w układach tłoczących instalacji, jednak znaczącą liczbę stanowią uszkodzenia układów hydraulicznych sterowania mechanizacją skrzydła samolotu (rys.1).

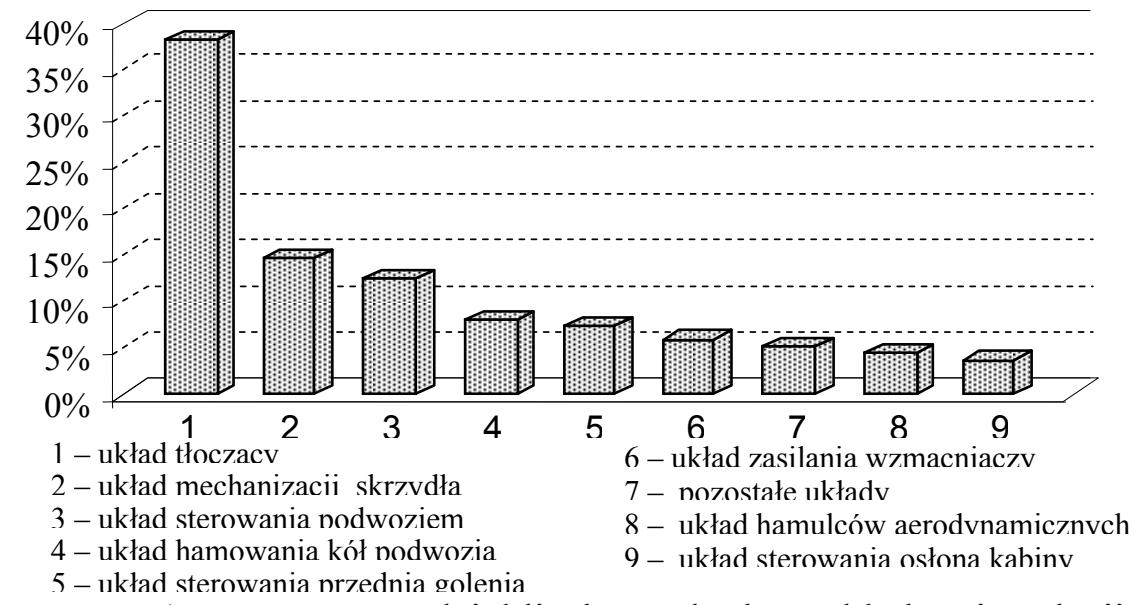

Rys. 1. Procentowy udział liczby uszkodzeń układów instalacji hydraulicznych samolotów lotnictwa SZ RP ( $1.10 .2002 \div 30.09 .2005)$ [7] 
Badania oraz doświadczenia eksploatacyjne wskazują, że niewłaściwa praca mechanizacji skrzydła może być spowodowana przez: $[5,7,11]$ :

$>$ uszkodzenia układu kinematycznego i zawieszenia elementów mechanizacji skrzydła;

nieprawidłową pracę układu hydraulicznego.

Nieprawidłowa praca układu hydraulicznego mechanizacji skrzydła może być spowodowane głównie przez:

$>$ przecieki zewnętrzne (nieszczelność układu transmisji cieczy hydraulicznej);

przecieki wewnętrzne (nieszczelności w elementach wykonawczych).

\section{Model matematyczny układu hydraulicznego klap skrzydła samolotu}

\section{Do modelowania uktadu hydraulicznego klap skrzydtowych przyjęto} nastęujące zalożenia:

$>$ w całym zakresie pracy układu obowiązuje jeden rodzaj przepływu;

$>$ nie występuje kawitacja;

$>$ pominięto sprężystość cieczy oraz ścianek przewodów hydraulicznych;

$>$ przepływ przez szczeliny jest laminarny i proporcjonalny do ciśnienia;

$>$ czynnik roboczy posiada stałe własności fizyczne;

$>$ efekt dławieniowy sprowadzono do dławienia przez zawór rozdzielczy;

$>$ pominięto pulsacyjny charakter pracy pompy;

$>$ pominięto straty na odcinku zawór rozdzielczy - siłownik;

$>$ zastosowano zawór rozdzielczy o zerowym przykryciu.

Uwzględniając powyższe założenia, przyjęto uproszczony schemat układu wraz z oznaczeniami przedstawiony na rysunku 2.

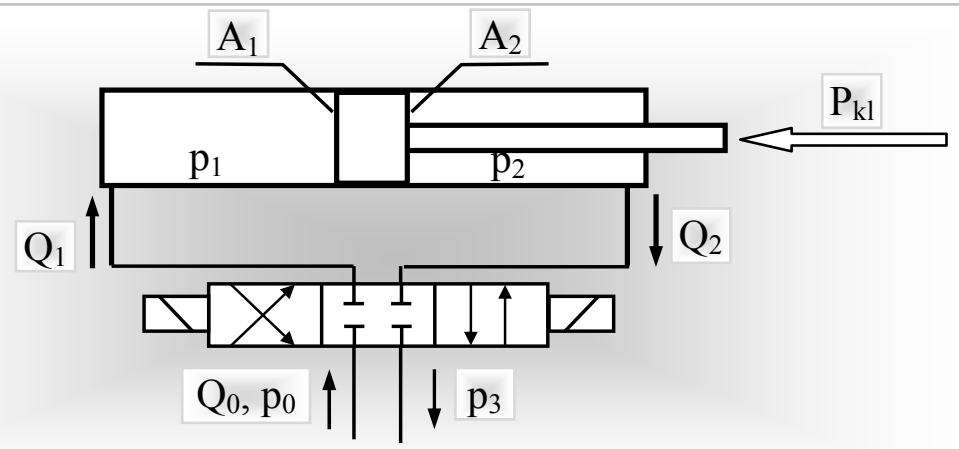

Rys. 2. Schemat ideowy układu hydraulicznego klap skrzydłowych

Proces opracowania modelu matematycznego opiera się na bilansie natężeń przepływu cieczy roboczej oraz równaniu ruchu zespołu napędowego siłownika. 
Bilans natężeń przepływu:

$$
\begin{aligned}
& Q_{1}=Q_{P}+Q_{H 1}+Q_{S 1}+Q_{V} \\
& Q_{2}=Q_{H 2}+Q_{S 2}+Q_{V}
\end{aligned}
$$

Bilans ruchu zespołu napędowego siłownika:

$$
m \frac{d^{2} y}{d t^{2}}+B \frac{d y}{d t}+P_{S}=A_{1} p_{1}-A_{2} p_{2}
$$

Wprowadzając do bilansów natężeń przepływu zależności na poszczególne wydatki cieczy, a następnie po zlinearyzowaniu zależności na wydatek cieczy zasilającej siłownik oraz po zastosowaniu przekształcenia Laplace'a do równań $(1 \div 3)$, transmitancja układu przyjmie ostatecznie postać [3]:

$$
\begin{aligned}
& G(s)=\frac{Y(s)}{X(s)}=\frac{K}{T_{2} s^{2}+T_{1} s+1} \\
& K=\frac{\alpha \pi^{2} b \sqrt{p_{0}}\left(2 D^{2}-d^{2}\right)}{16 K_{V} N_{K L}} \quad T_{1}=\frac{m}{N_{K L}} \quad T_{2}=\frac{B}{N_{K L}}+\frac{A^{2}}{2 K_{V} N_{K L}}\left(2-\frac{d^{2}}{D^{2}}\right)
\end{aligned}
$$

Gdzie: B - wspótczynnik tarcia wiskotycznego; $b$ - średnica suwaka zaworu rozdzielczego; $D, d$-średnica tłoka i tłoczyska; $K_{V}$ - wspótczynnik strat objętościowych; $m$ - masa napędzanego zespołu; $N_{K L}$ - współczynnik obciażenia klapy; $p_{0}$ - ciśnienie robocze;; $\alpha$ - wspótczynnik przepływu;; $\lambda$ współczynnik podziału natężenia przepływu.

Wartości współczynników transmitancji układu $\mathrm{K}, \mathrm{T}_{1}, \mathrm{~T}_{2}$ są funkcjami rzeczywistych parametrów układu. Dzięki temu, opracowany model matematyczny umożliwia badania symulacyjne układów hydraulicznych sterowania klapami skrzydłowymi różnych samolotów.

\section{Badania symulacyjne dynamiki układu klap skrzydłowych}

\subsection{Metodyka badań symulacyjnych}

Badania przeprowadzono według następującej procedury:

$>$ dla danego rodzaju zaburzenia, wprowadzono do programu komputerowego Matlab-Simulink dane układu hydraulicznego, uwzględniając zaburzenia o różnej wartości;

z wykresów odczytano wartości przemieszczenia się trzona i obliczono różnicę przemieszczeń trzonów siłowników;

$\Delta y(t)=y_{0}(t)-y_{Z}(t)$ 
obliczono różnicę sił aerodynamicznych na klapach skrzydłowych:

$\Delta \boldsymbol{P}_{k l}(t)=\boldsymbol{P}_{k l 0}(t)-\boldsymbol{P}_{k l Z}(t)$

\subsection{Badania symulacyjne uktadu z uwzględnieniem przecieków wewnętrznych w silowniku}

Zwiększone przecieki wewnętrzne w siłowniku, mogą wystapić z powodów: starzenie się materiałów $\mathrm{z}$ których wykonano uszczelnienia; zanieczyszczenia cieczy roboczej; zastosowanie cieczy roboczej o własnościach niezgodnych $\mathrm{z}$ warunkami technicznymi układu; błędy $\mathrm{w}$ technologii produkcji (np. zwiększona chropowatość wewnętrznej powierzchni siłownika). Przecieki wewnętrzne powodują zmniejszenie się objętościowego natężenia przepływu w siłowniku o wartość:

$Q_{V}=K_{V}\left(p_{1}-p_{2}\right)$

Wzrost przecieków wewnętrznych wyrażono jako procentowy przyrost współczynnika strat objętościowych $\mathrm{K}_{\mathrm{v}} \quad \mathrm{W}$ stosunku do wartości odpowiadającej prawidłowej pracy układu:

$$
\Delta K_{V}=\left(\frac{K_{V Z}}{K_{V 0}}-1\right) \cdot 100 \%
$$

Niesymetryczność wychylenia klap jest przyczyną powstania na nich różnicy sił aerodynamicznych (rys.3 i 4)

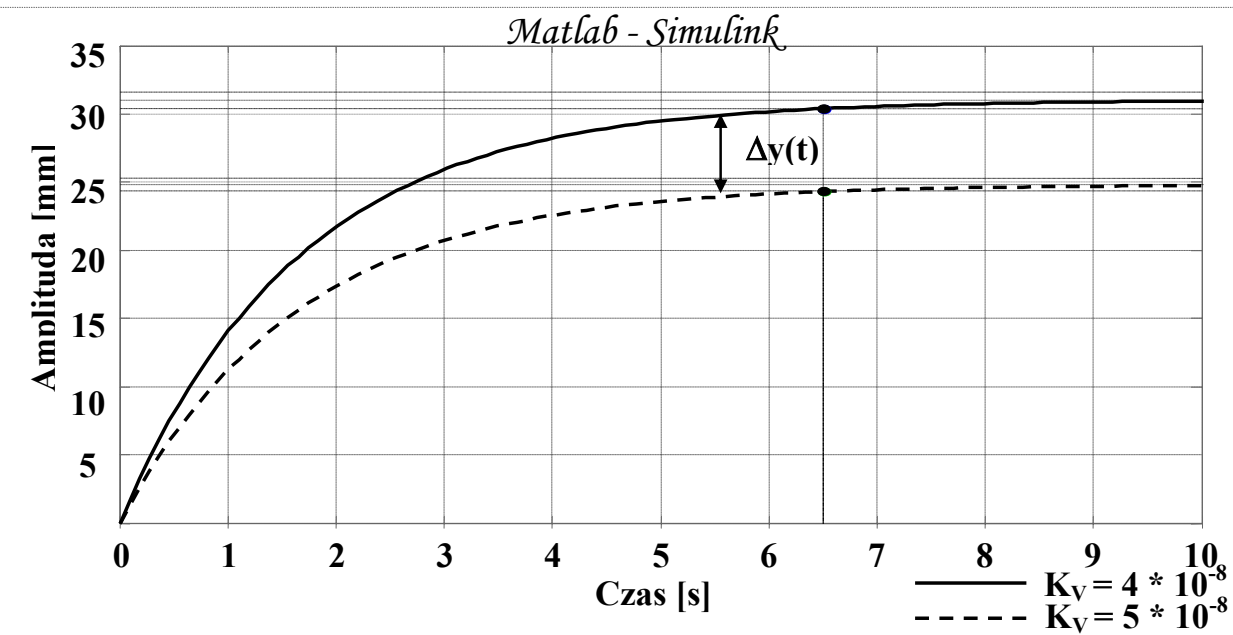

Rys.3. Dynamika układu przy wzroście przecieków wewnętrznych 


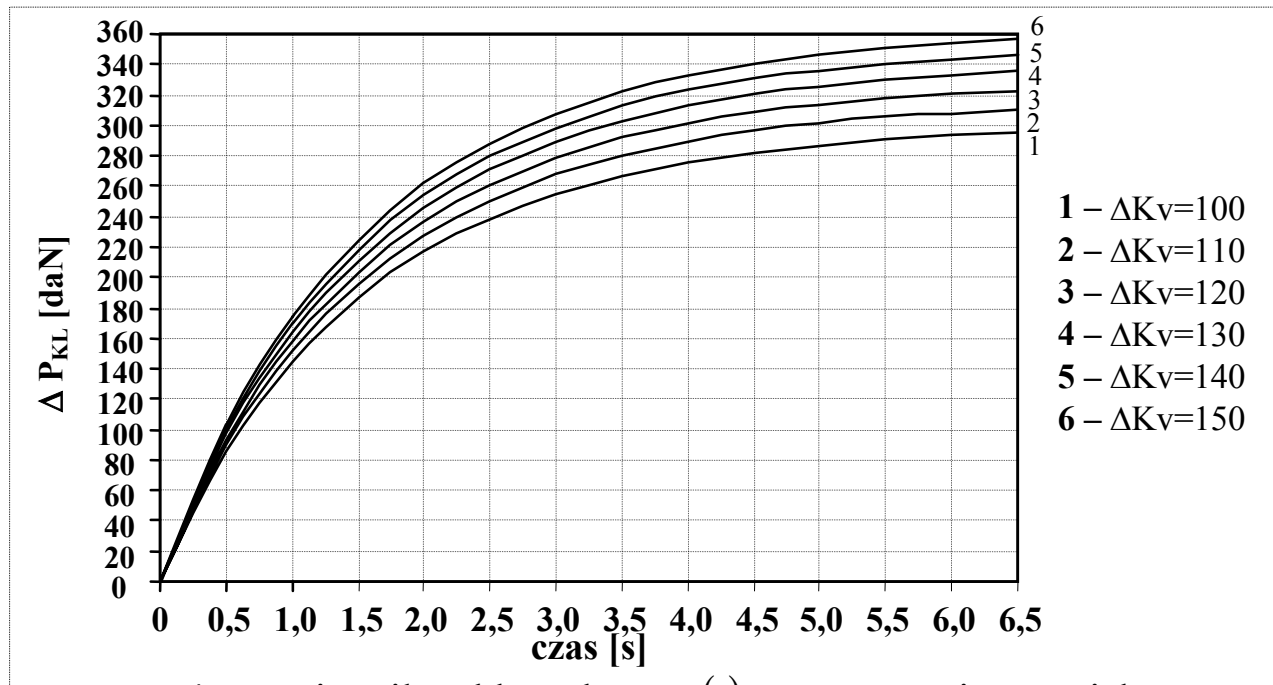

Rys.4. Różnica sił na klapach $\Delta P_{K L}(t)$ przy wzroście przecieków wewnętrznych

\subsection{Badania symulacyjne uktadu z uwzględnieniem przecieków zewnętrznych}

Jedną z możliwych niesprawności układu hydraulicznego może być jego nieszczelność powodująca wystapienie przecieków zewnętrznych cieczy roboczej.

Do głównych przyczyn wystąpienia nieszczelności układu hydraulicznego można zaliczyć:

zmęczeniowe pękniecie przewodów hydraulicznych;

nieszczelności w miejscu łączenia przewodów;

błędy w technologii wykonania przewodów;

uszkodzenia mechaniczne przewodów;

inne.

Badania dynamiki układu klap wykonano przy następujących założeniach:

$>$ wyciek cieczy roboczej wystapi w linii zasilania siłownika jednej z klap;

$>$ nieszczelność układu w jednej linii zasilania nie ma wpływu na działanie układu drugiej klapy skrzydłowej;

wielkość wycieku podczas pracy układu jest stała i wyrażono ją przez spadek ciśnienia roboczego $\Delta \mathrm{p}$.

Pojawienie się przecieków zewnętrznych, jako skutek nieszczelności układu hydraulicznego, jest przyczyną niesynchroniczności ruchu trzonów siłowników klap skrzydłowych (rys.5). 


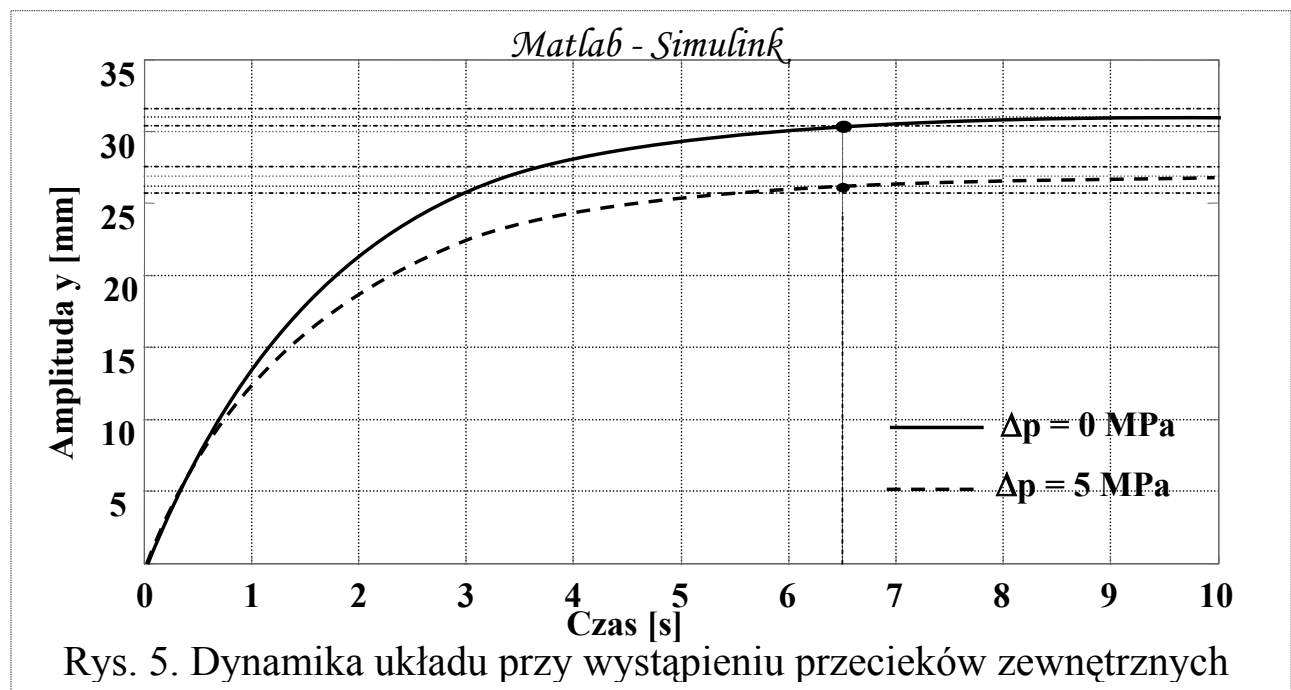

Niesymetryczność wychylenia klap skrzydłowych powoduje, że powstaje na nich różnica sił aerodynamicznych (rys. 6).

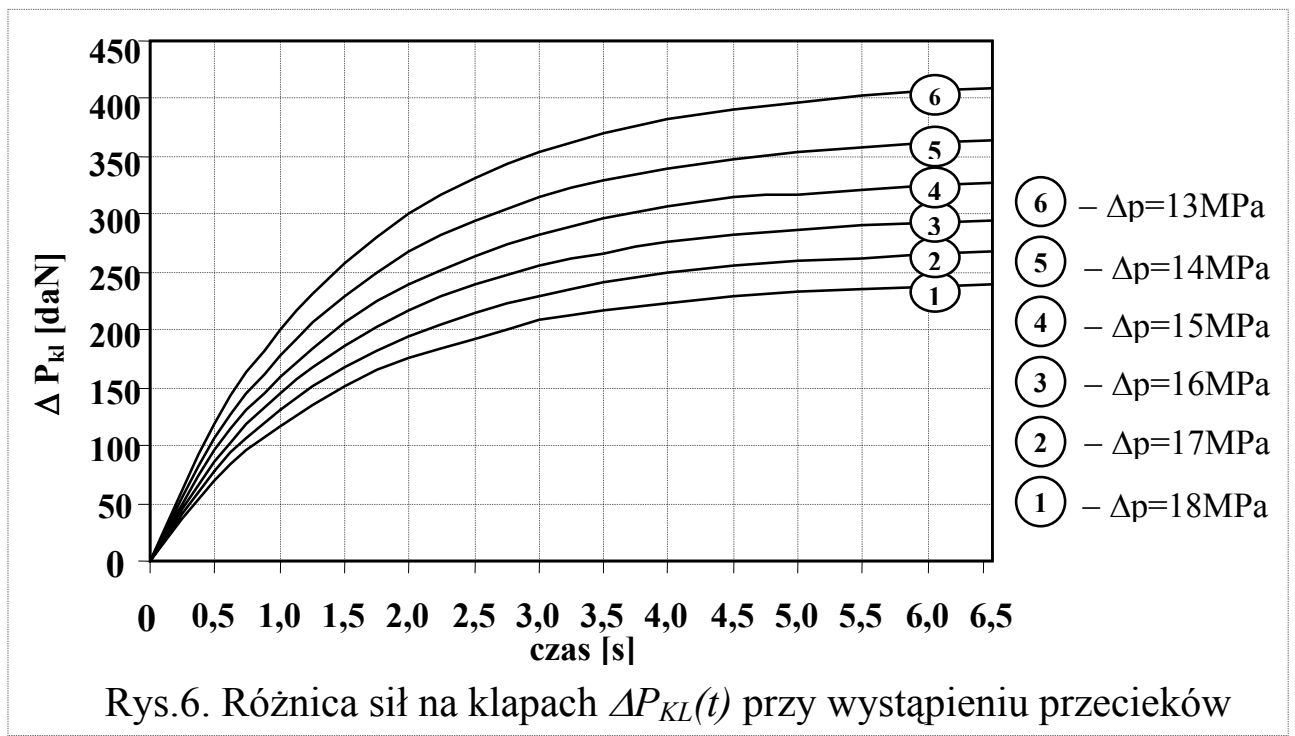




\section{Podsumowanie}

$\mathrm{Na}$ podstawie analizy konstrukcyjnej układu hydraulicznego klap skrzydłowych, wyników badań symulacyjnych oraz obliczeń, dla poszczególnych rodzajów zaburzeń, można wysnuć następujące wnioski:

a) Zaburzenia $w$ postaci zwiększonych przecieków wewnętrznych w sitowniku:

występuje niesymetryczność wychylenia klap w całym zakresie czasu pracy układu;

różnica kątów wychylenia klap wzrasta wraz z czasem działania układu;

> wzrost przecieków wewnętrznych powoduje zwiększanie różnicy kątów wychylenia klap;

$>$ klapy pozostają wychylone niesymetrycznie po osiagnięciu przez jedną z nich maksymalnego kąta wychylenia;

największe przyrosty różnicy kątów wychylenia klap występują w początkowej fazie pracy układu.

b) Zaburzenia w postaci przecieków zewnętrznych:

występuje niesymetryczność wychylenia klap w całym zakresie czasu pracy układu;

największe przyrosty różnicy kątów wychylenia klap występują w początkowej fazie pracy układu;

klapy pozostają wychylone niesymetrycznie po osiagnięciu przez jedną z nich maksymalnego kąta wychylenia.
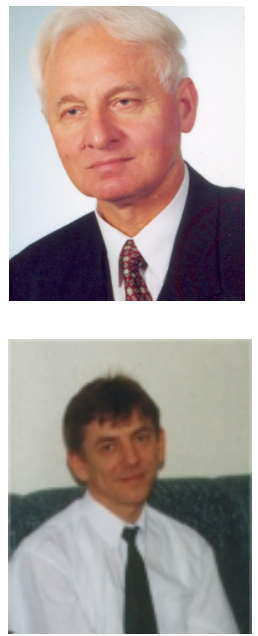

Ass Prof. Józef BLACHNIO, Eng. Air Force Institute of Technology Warsaw.

Represented fields, disciplines, specialties of science:

- Machine building and operation;

- Materials engineering;

- Technical diagnostics;

- Airplanes, helicopters, aircraft engines.

PhD GRONCZEWSKI Andrzej. Wroclaw University of Technology. Specialization: aerodynamics, mechanic of flight, construction of aircraft. 